\title{
Gout as a trigger for acute Charcot neuro-osteoarthropathy?
}

\author{
SHAILESH GOHIL, RAJESH JOGIA, RACHEL BERRINGTON, MARIE-FRANCE KONG
}

\begin{abstract}
Patients with diabetes and a painful, hot, swollen foot can sometimes present a diagnostic challenge. Gout can often present in a similar fashion to diabetic foot infections or acute Charcot neuro-osteoarthropathy, and cases have been described where patients with Charcot neuro-osteoarthropathy were misdiagnosed as having gout, leading to treatment delay. We describe a patient who presented with a painful, swollen, warm foot who did not respond to initial treatment with antibiotics. Improvement in his symptoms occurred following treatment for gout, however he then went on to develop Charcot neuroosteoarthropathy. As far as we are aware, this is the first case described in the literature where acute gout may have triggered acute Charcot neuro-osteoarthropathy. It is important to bear in mind that more than one pathology may be present in a patient at the same time or may closely follow one another.
\end{abstract}

Key words: Charcot neuro-osteoarthropathy, diabetes, foot, gout, infection, antibiotics

\section{Introduction}

Gout is an inflammatory arthritis caused by the build-up of sodium biurate crystals within joint spaces. ${ }^{1}$ The first metatarsophalangeal joint is classically affected, with other joints being affected less frequently. Symptoms usually include an excruciatingly painful joint with erythema, swelling and warmth. On joint aspiration and polarised microscopy, negatively birefringent crystals are classically seen. ${ }^{2}$ Clinical factors associated with gout include type 2 diabetes mellitus, obesity, hyperuricaemia, impaired renal function and diuretic therapy. ${ }^{3,4}$ Interestingly, poorly controlled diabetes may reduce the risk of gout due to hyperglycaemia-induced polyuria and uricosuria. ${ }^{5}$ Patients with diabetes with peripheral neuropathy may not necessarily experience the pain expected, promoting a diagnostic challenge. Charcot neuro-osteoarthropathy is sometimes mislabelled as gout, adding to the challenge. ${ }^{6-8}$

Diabetes mellitus is the most common cause of Charcot

Department of Diabetes, University Hospitals of Leicester NHS Trust, Leicester, UK

Address for correspondence: Dr Marie-France Kong Department of Diabetes, University Hospitals of Leicester NHS Trust, Gwendolen Road, Leicester, LE5 4PW, UK.

E-mail: marie-france.kong@uhl-tr.nhs.uk

Br J Diabetes 2017;17:156-159

https://doi.org/10.15277/bjd.2017.146 neuro-osteoarthropathy affecting the foot. ${ }^{9}$ Peripheral neuropathy alongside a specific trigger induces acute localised inflammation within the foot leading to bone destruction, subluxation, dislocation and deformity. 10,11 Again, due to neuropathy caused by diabetes, pain may not be a predominant feature of a Charcot foot, however inflammation usually causes warmth and swelling of the joint. Inflammatory markers are not usually markedly raised. ${ }^{12}$ Triggers for Charcot neuro-osteoarthropathy are many; however, all involve some form of stress to the foot such as infection, surgery, injury or trauma. ${ }^{10}$

We present a case of gout in the foot which may have precipitated acute Charcot neuro-osteoarthropathy.

\section{Case description}

A 58-year-old Caucasian man with type 2 diabetes mellitus, obesity, hypertension, hypercholesterolaemia and previous left-sided Charcot neuro-osteoarthropathy presented to the multidisciplinary diabetic foot clinic at our University teaching hospital in September 2016. He had known secondary complications of diabetes including background retinopathy, peripheral neuropathy and erectile dysfunction. In addition, he had sustained fractures to both bases of the 5th metatarsals in 2013, which were stabilised with internal fixation. He had presented to the accident and emergency department three weeks previously with a swollen foot after having walked more than usual. There was pain in the plantar aspect of his foot with no visible wound. He had no recollection of any obvious injury. There was no temperature difference between the two feet. Foot radiographs did not show any new fractures or signs of Charcot neuroosteoarthropathy. A deep vein thrombosis was excluded by ultrasound sonography. Within two weeks his symptoms had progressed, with erythema and oedema extending up to his midcalf. His right foot became 2.5 degrees warmer than the left. His C-reactive protein (CRP) level was $107 \mathrm{mg} / \mathrm{L}$ (normal range 0-10) and his family doctor treated him with oral flucloxacillin for a presumed diagnosis of cellulitis. Although there was an initial improvement in his symptoms, the erythema, oedema and warmth did not improve despite his initial course of flucloxacillin and, later, teicoplanin (Figure 1). He was unable to put weight on his right foot. Repeat X-rays only highlighted the old fracture with no new changes compared to the X-ray performed a month previously (Figure 2). CRP had only fallen to $87 \mathrm{mg} / \mathrm{L}$ after antibiotic therapy. Due to slow resolution, a suspicion of gout affecting his midfoot was raised and Charcot neuroosteoarthropathy was still considered a possible diagnosis. His urate level was noted to be raised at $439 \mu \mathrm{mol} / \mathrm{L}$ (normal range 
Figure 1. Appearance of foot following course of flucloxacillin

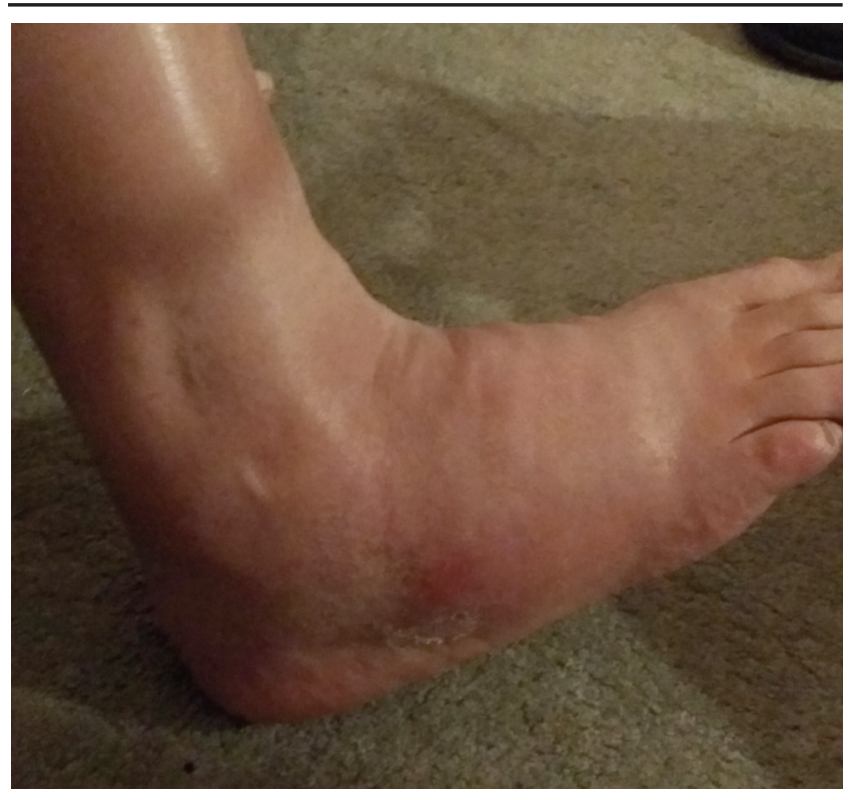

Figure 2. Lateral X-ray of right foot on initial presentation

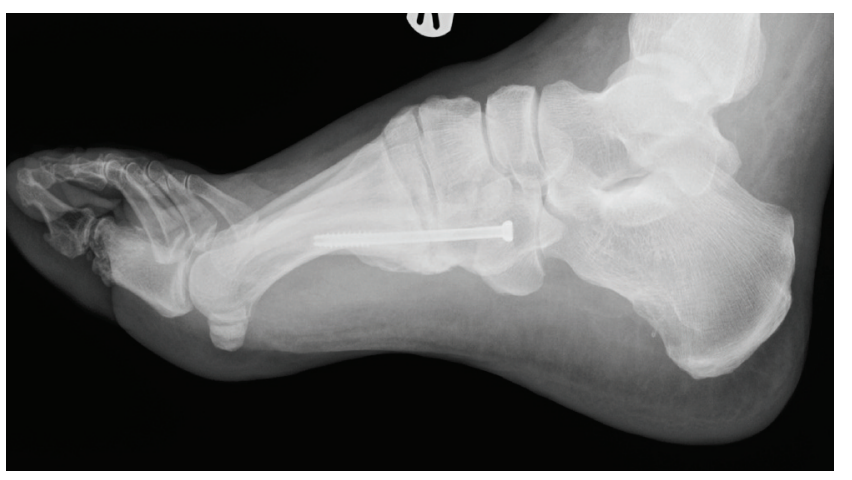

200-430) in June 2016 and he was on bendroflumethiazide. Colchicine was therefore prescribed alongside his antibiotics. An MRI of his foot was requested. After a week there was some improvement in the oedema and he reported that the foot was less painful. However, the foot remained warm and the movement in his right foot was still restricted. His right foot was 3.5 degrees warmer than the left. His CRP had come down to $14 \mathrm{mg} / \mathrm{L}$. One more week of teicoplanin was prescribed and he was initiated on prednisolone $30 \mathrm{mg}$ once daily for one week alongside colchicine $500 \mu \mathrm{g}$ twice daily after discussion with the rheumatology team. Following the course of prednisolone, there was continued improvement in his symptoms although his foot remained warm. He was given four weeks of colchicine $500 \mu \mathrm{g}$ twice daily in total. When reviewed again a week later, the pain and swelling of his right foot and leg was settling and he had better movement in his right foot.
Figure 3. Image of feet after hearing crack

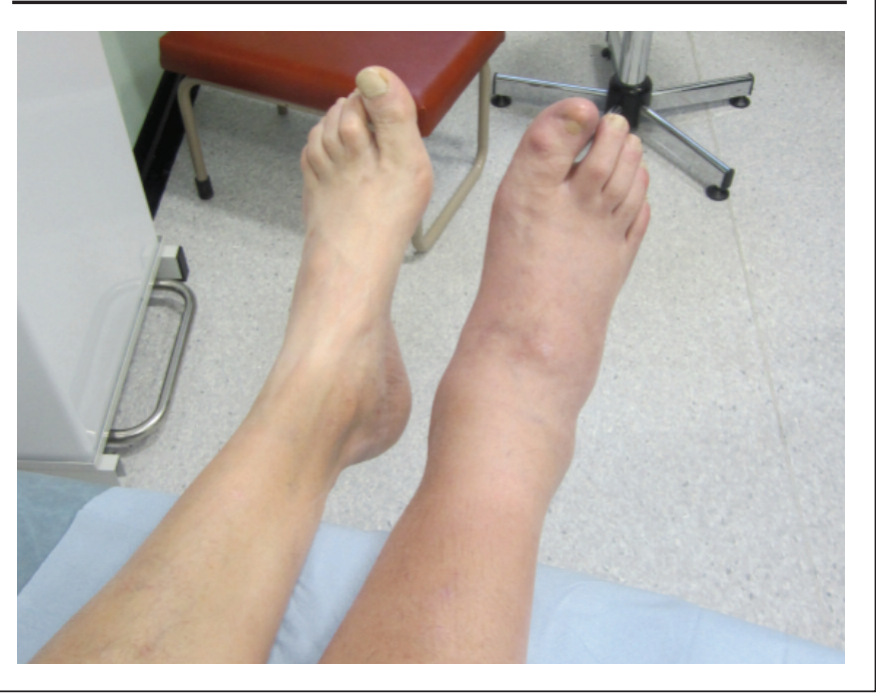

Figure 4. Lateral image of right foot after hearing crack

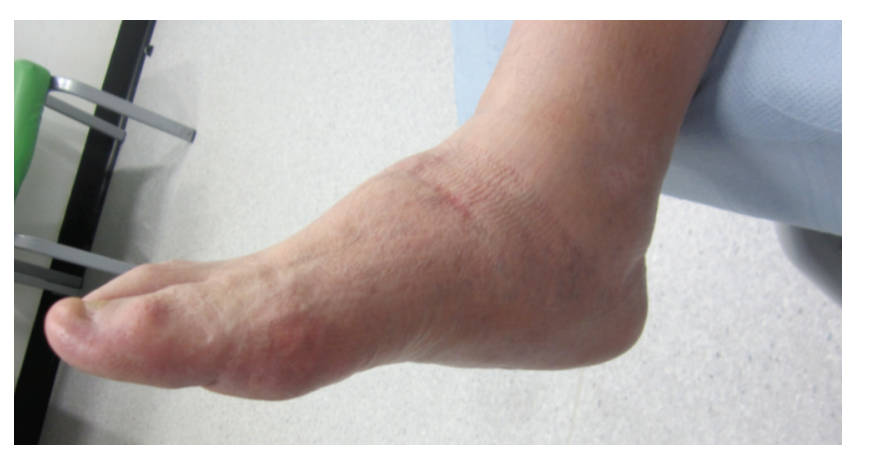

Figure 5. Lateral X-ray of right foot showing acute changes of Charcot neuro-osteoarthropathy in the midfoot

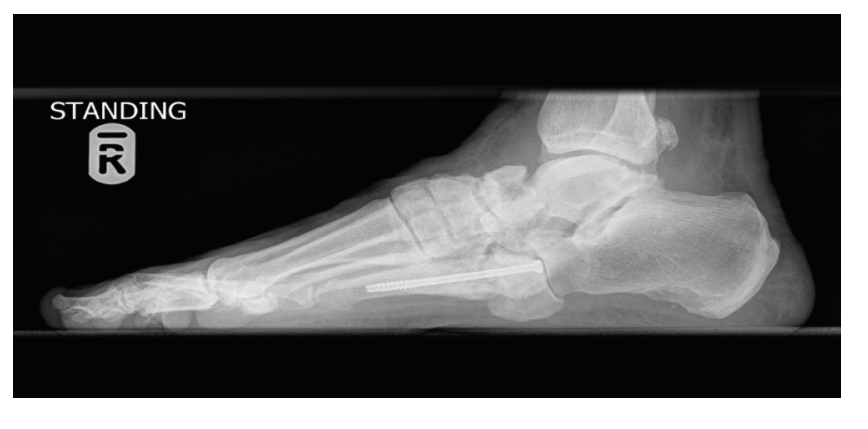

At review a month later he reported that he heard a crack in his right foot the week before and he had attended the orthopaedic clinic (Figures 3 and 4). His foot X-ray showed changes of Charcot neuro-osteoarthropathy in the midfoot (Figure 5). The swelling in his right leg had gone down and the swelling in his right foot had also improved, but the right foot remained 
Figure 6. STIR image showing bone marrow oedema in the tarsal bones. Subluxation of the navicular bone is also shown

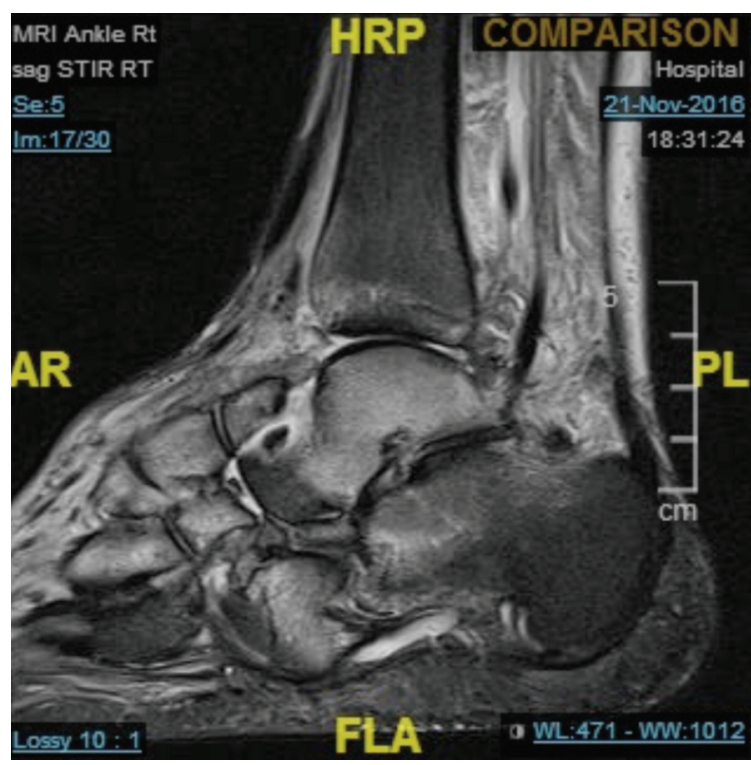

Figure 7. Appearance of Charcot neuro-osteoarthropathy right foot resolving in between cast changes

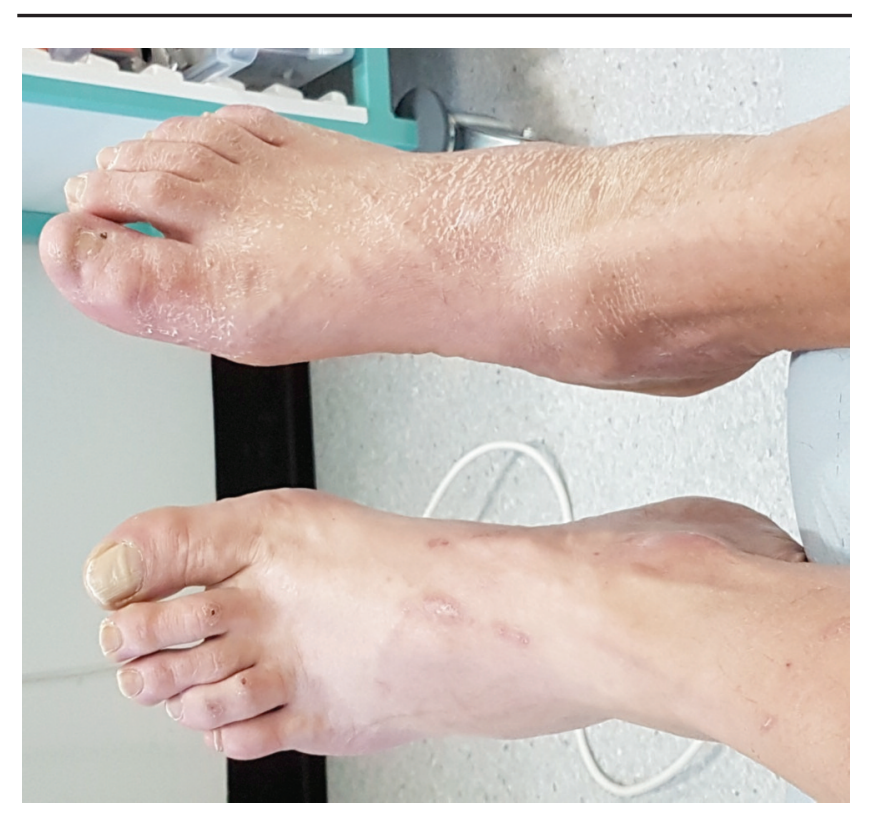

warmer than the left. He was put in a non-removable belowknee cast. The MRI foot scan which we had requested when we saw him in clinic initially had been performed two days before his clinic appointment and this confirmed active Charcot neuroosteoarthropathy (Figure 6). He remained in a cast for six months until the temperature difference between the feet was less than two degrees (Figure 7).

\section{Discussion}

As far as we know, Charcot neuro-osteoarthropathy following an episode of gout has not been described previously. Neuropathy is invariably a feature of Charcot neuro-osteoarthropathy, with diabetes mellitus being the most common cause. ${ }^{9}$ Trauma or stress of any nature can precipitate the initial uncontrolled inflammation preceding an episode of Charcot neuroosteoarthropathy. ${ }^{13}$ Therefore, it is not unreasonable to suggest that gout can be a trigger for this process, especially with its associated bony changes.

A diagnostic challenge is presented when a patient with diabetes with peripheral neuropathy presents with pain, swelling and erythema in their foot.14,15 The initial instinct is to give antibiotics to treat an infective cause; however, gout can also cause similar symptomatology. Symptoms due to gout typically start to subside within 3-10 days and, if antibiotics have been given, the improvement is often attributed to the antibiotics. Therefore, a diagnosis of gout can be missed. If Charcot neuroosteoarthropathy was to develop subsequently, the trigger would then be put down to infection rather than gout. In this case, although the course of prednisolone was given to treat gout, it may also have caused a degree of improvement if he had concurrent acute Charcot neuro-osteoarthropathy. There is also the possibility that he had Charcot neuro-osteoarthropathy from the beginning.

\section{Conclusion}

Our patient presented with a painful, oedematous, erythematous, warm foot which did not initially respond to antibiotics. Upon reviewing his diagnosis, treatment for acute gout was initiated which led to some improvement in his symptoms; however, his foot still remained warm. This may have represented resolution of gout and new presentation of acute Charcot neuroosteoarthropathy. Over time, the acute Charcot neuroosteoarthropathy became more clinically obvious and was managed accordingly. Differentiating between infection, gout and Charcot neuro-osteoarthropathy can be difficult and many have described Charcot neuro-osteoarthropathy as being misdiagnosed as gout. However, it is possible for these entities to be present at the same time or for one to lead to another; in our case gout possibly led to Charcot neuro-osteoarthropathy. It is therefore important not to exclude diagnoses and to remember that dual pathologies may co-exist or may occur in quick succession.

Acknowledgements We thank Professor Fran Game, Consultant Diabetologist and Clinical Director of R\&D, Derby Teaching Hospitals NHS Foundation Trust, UK and Honorary Professor, University of Nottingham, UK for her helpful comments and time for reviewing our manuscript.

\section{Conflict of interest None \\ Funding sources None.}

\section{References}

1. Choi HK, Mount DB, Reginato AM. Pathogenesis of gout. Ann Intern Med 2005;143:499-516.

https://doi.org/10.7326/0003-4819-143-7-200510040-00009 
2. Chen LX, Schumacher HR. Current trends in crystal identification. Curr Opin Rheumatol 2006;18:171-3. http://dx.doi.org/10.1097/01.bor.0000209430.59226.0f

3. Singh JA, Reddy SG, Kundukulam J. Risk factors for gout and prevention: a systematic review of the literature. Curr Opin Rheumatol 2011;23:192202. http://dx.doi.org/10.1097/BOR.0b013e3283438e13

4. Roddy E, Zhang W, Doherty M. The changing epidemiology of gout. Nat Clin Pract Rheumol 2007:3:443-9.

http://dx.doi.org/10.1038/ncprheum0556

5. Rodriguez G, Soriano L, Choi H. Impact of diabetes against the future risk of developing gout. Ann Rheum Dis 2010;69:2090-4. http://dx.doi.org/10.1136/ard.2010.130013

6. Pakarinen TK, Laine HJ, Honkonen SE, et al. Charcot arthropathy of the diabetic foot. Current concepts and review of 36 cases. Scand J Surg 2002:91:195-201. http://dx.doi.org/10.1177/145749690209100212

7. Gill GV, Hayat H, Majid S. Diagnostic delays in diabetic Charcot arthropathy. Pract Diabetes 2004:21:261-2. https://doi.org/10.1002/pdi.677

8. Baglioni P, Malik M, Okosieme OE. Acute Charcot foot. BMJ 2012; 344:e1397. http://dx.doi.org/10.1136/bmi.e1397

9. Frykberg RG, Kozak GP. Neuropathic arthropathy in the diabetic foot.
Am Fam Physician 1978;17:105-13.

10. Rogers LC, Frykberg RG, Armstrong DG, et al. The Charcot foot in diabetes. Diabetes Care 2011;34:2123-9. http://dx.doi.org/10.2337/dc11-0844

11. Jeffcoate WJ, Game F, Cavanagh PR. The role of proinflammatory cytokines in the cause of neuropathic osteoarthropathy (acute Charcot foot) in diabetes. Lancet 2005;366:2058-61. http://dx.doi.org/10.1016/S0140-6736(05)67029-8

12. Petrova NL, Moniz C, Elias DA, et al. Is there a systemic inflammatory response in the acute Charcot foot? Diabetes Care 2007;30:997-8.

13. Kaynak G, Birsel O, Güven MF, Ögüt T. An overview of Charcot foot pathophysiology. Diabetic Foot Ankle 2013;4:21117. http://dx.doi.org/10.3402/dfa.v4i0.21117

14. Barksfield R, Gallagher K, Pasapula C. Silent gout: an unusual presentation in diabetic neuropathy. Foot (Edinb) 2012;22:264-6. http://dx.doi.org/10.1016/j.foot.2012.06.002

15. Crasto W, Jogia $R$, Jackson $S$, et al. Ulcerated gout masquerading as a non healing diabetic foot ulcer: a case series. $\mathrm{Br} J$ Diabetes Vasc Dis 2014:14:21-5. http://dx.doi.org/10.15277/bjdvd.2014.004

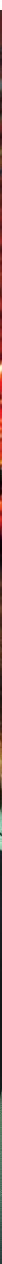

(c) 2017 Roche Diabetes Care Limited. All rights reserved.

Distributed in the UK by Roche Diabetes Care Limited. Roche Diabetes Care Limited, Charles Avenue, Burgess Hill, West Sussex, RH15 9RY, UK.

Company registration number: 9055599 . www.accu-chek.co.uk/eversense 